\title{
Mathematical Reconstruction of a Traffic Crash
}

Benjamin Covert
University of South Florida, bcovert@usf.edu

\author{
Advisors: \\ Arcadii Grinshpan, Mathematics and Statistics \\ Timothy Sleyzack, Traffic Homicide Investigator, Florida Highway Patrol, Tampa \\ Problem Suggested By: James Covert
}

Field of Study for Problem Suggester: Traffic Homicide Investigator, Florida Highway Patrol, Tampa

Follow this and additional works at: https://digitalcommons.usf.edu/ujmm

Part of the Mathematics Commons

UJMM is an open access journal, free to authors and readers, and relies on your support: Donate Now

\section{Recommended Citation}

Covert, Benjamin (2021) "Mathematical Reconstruction of a Traffic Crash," Undergraduate Journal of Mathematical Modeling: One + Two: Vol. 11: Iss. 2, Article 2.

DOI: https://doi.org/10.5038/2326-3652.11.2.4930

Available at: https://digitalcommons.usf.edu/ujmm/vol11/iss $2 / 2$ 


\title{
Mathematical Reconstruction of a Traffic Crash
}

\author{
Abstract \\ The objective is to find the impact speeds of two motor vehicles involved in a traffic crash. The \\ calculations take into account the approach (pre-collision) and departure (post collision) angles, as well \\ as weights and post collision speeds of both vehicles. The data is provided by Timothy Sleyzack who \\ investigated this traffic collision. The conclusions confirm the validity of the use of Conservation of Linear \\ Momentum in the field of traffic crash reconstruction.
}

\section{Keywords}

traffic collision, Conservation of Linear Momentum, impact speed, post collision speed, pre-collision and post collision angles, coefficient of restitution

\section{Creative Commons License}

(c) (1)(9)

This work is licensed under a Creative Commons Attribution-Noncommercial-Share Alike 4.0 License. 


\section{PROBLEM STATEMENT}

Use Conservation of Linear Momentum to reconstruct a traffic crash mathematically and accurately.

\section{MOTIVATION}

In the field of traffic crash reconstruction, one of the most commonly asked questions of the investigator is: What is the speed of each vehicle, especially the striking vehicle, at the time of the collision? It is very important for the investigator to have an accurate account of speeds of vehicles as it helps to adequately analyze and conclude on events and causes in a collision. Investigators commonly find witness accounts as to a vehicle's speed to be conflicting. To address this problem effectively, a mathematical approach is preferred to witness testimony.

\section{MATHEMATICAL DESCRIPTION AND SOLUTION APPROACH}

The solution approach is based on Conservation of Linear Momentum. Linear momentum is a product of the mass and velocity of an object. Momentum is a vector which points in the same direction as velocity. The total amount of momentum never changes, and this property is called conservation of momentum.

While reconstructing the traffic crash, I first determine the approach (pre-collision) and departure (post collision) angles for each vehicle from a scale diagram of the crash scene which is provided by Timothy Sleyzack who investigated the crash (see Appendices). So the first thing that needs to be done is to find all four of the angles $(\alpha, \psi, \theta, \phi)$ that are required for the mathematical equations (A) and (B) below. The next thing is to obtain the weights of the vehicles and their post collision speeds. After that, it is a matter of plugging in the variables to get the desired values for the pre-collision speeds of the vehicles. The final step is to calculate the coefficient of restitution.

After determining each vehicle's approach and departure angle, I calculate the sine and cosine values for each angle. I then use the weight of both vehicles and their post collision energy loss into the following mathematical equations.

$$
\mathrm{S}_{2}=\frac{\left(\mathrm{W}_{1}\right)\left(\mathrm{S}_{3}\right)(\operatorname{Sin} \theta)}{\left(\mathrm{W}_{2}\right)(\operatorname{Sin} \psi)}+\frac{\left(\mathrm{S}_{4}\right)(\operatorname{Sin} \phi)}{\operatorname{Sin} \psi}
$$

For equation $(A)$, the pre-collision speed of vehicle-2 $\left(S_{2}\right)$ is equal to the weight of vehicle-1 $\left(W_{1}\right)$, multiplied by the post collision speed of vehicle-1 $\left(S_{3}\right)$, multiplied by the sine of the departure angle of vehicle-1 $(\theta)$; divided by the product of the weight of vehicle-2 $\left(W_{2}\right)$ and the 
sine of the approach angle of vehicle-2 $(\psi)$. That calculation is then added to the product of the post collision speed of vehicle-2 $\left(\mathrm{S}_{4}\right)$ and the sine of the departure angle of vehicle-2 $(\phi)$, divided by the sine of the approach angle of vehicle-2 $(\psi)$.

$$
\mathrm{S}_{1}=\frac{\left(\mathrm{S}_{3}\right)(\operatorname{Cos} \theta)}{\operatorname{Cos} \alpha}(+) \frac{\left(\mathrm{W}_{2}\right)\left(\mathrm{S}_{4}\right)(\operatorname{Cos} \phi)}{(-)} \frac{\left(\mathrm{W}_{2}\right)\left(\mathrm{S}_{2}\right)(\operatorname{Cos} \psi)}{\left(\mathrm{W}_{1}\right)(\operatorname{Cos} \alpha)}
$$

For equation $(\mathrm{B})$, the pre-collision speed of vehicle-1 $\left(\mathrm{S}_{1}\right)$ is equal to the post collision speed of vehicle-1 $\left(\mathrm{S}_{3}\right)$, multiplied by the cosine of the departure angle of vehicle-1 $(\theta)$; divided by the cosine of the approach angle of vehicle-1 $(\alpha)$. That calculation is then added to the product of the weight of vehicle-2 $\left(\mathrm{W}_{2}\right)$, the post collision speed of vehicle-2 $\left(\mathrm{S}_{4}\right)$ and the cosine of the departure angle of vehicle-2 $(\phi)$; divided by the weight of vehicle-1 $\left(\mathrm{W}_{1}\right)$ multiplied by the cosine of the approach angle of vehicle-1 $(\alpha)$. That calculation is then subtracted by the product of the weight of vehicle-2 $\left(\mathrm{W}_{2}\right)$, the pre-collision speed of vehicle-2 $\left(\mathrm{S}_{2}\right)$ and the cosine of the approach angle of vehicle-2 $(\psi)$; divided by the product of the weight of vehicle-1 $\left(\mathrm{W}_{1}\right)$ and the cosine of the approach angle of vehicle-1 $(\alpha)$.

(C) $\quad \mathrm{e}=\underline{\left(\mathrm{S}_{3}\right)-\left(\mathrm{S}_{4}\right)}$

$\left(\mathrm{S}_{1}\right)-\left(\mathrm{S}_{2}\right)$

For equation (C), the coefficient of restitution (e) is the difference of the post collision speeds of vehicle-1 $\left(\mathrm{S}_{3}\right)$ and vehicle-2 $\left(\mathrm{S}_{4}\right)$ divided by the difference of the pre-collision speeds of vehicle$1\left(\mathrm{~S}_{1}\right)$ and vehicle-2 $\left(\mathrm{S}_{2}\right)$.

\section{DISCUSSION}

I calculated the impact speed of the target vehicle (vehicle-2) to be 21.96 miles-per-hour and that of the striking vehicle (vehicle-1) to be 40.85 miles-per-hour. To ensure the accuracy of results, two mathematical approaches are used. The first, Coefficient of Restitution, with a desired value between zero and one, produces a result of 0.15 . The second mathematical approach, Vector Sum Analysis, where a similar value for each vehicles' change in momentum $(\Delta \mathrm{M})$ is desired, results in identical values.

To further ensure the accuracy of my calculations, two electronic software calculations are used. The first one is Rec-Tec Professional Accident Reconstruction Software. Rec-Tec requires the input of each vehicles' weight, approach angle, departure angle and post collision speed to calculate an impact speed of 40.97 miles-per-hour for vehicle-1 and 22.35 miles-per-hour for vehicle-2. The second electronic software that is used to ensure the accuracy of my results is the review of each vehicle's Crash Data Retrieval System Report (Bosch), provided by Timothy Sleyzack. The Crash Data Retrieval System is often referred to as the Airbag Control Module or 
the vehicle's Black Box. This provides data such as a vehicle's speed, the time that an airbag deployed, up to five seconds prior to the deployment of the airbags or collision. The Crash Data Retrieval System denotes an impact speed of 37 miles-per-hour for vehicle-1 and a speed of 14 miles-per-hour for vehicle-2 (see below).

While reconstructing the traffic collision, my project objective, which is to calculate each vehicles' impact speed, is met. It confirms that the use of Conservation of Linear Momentum in the field of traffic crash reconstruction is a useful and accurate tool for a crash investigator.

\section{CONCLUSION AND RECOMMENDATIONS}

While the impact speed calculated for vehicle-1 is close (within 3 miles-per-hour) to the impact speed denoted in the Electronic Data Retrieval Report, the impact speed calculated for vehicle-2 is further (7 miles-per-hour) from the impact speed denoted in the Electronic Data Retrieval Report. This discrepancy can be attributed to the fact that vehicle-2's approach angle, which relies on physical evidence such as tire marks and swerve marks, can be susceptible to error, whereas the approach angle for the striking vehicle is always zero degrees.

For someone looking to do the same project I have a few recommendations. To obtain accurate results, when taking the angles into consideration, the angles should be measured multiple times. This will ensure that the angles have been measured effectively.

In conclusion, the importance of accurately determining approach and departure angles is significant when using Conservation of Linear Momentum. 


\section{NOMENCLATURE}

Variables used in Conservation of Linear Momentum

\begin{tabular}{|l|l|l|}
\hline W & Weight & Pounds (lbs.) \\
\hline$\alpha$ & Approach Angle Vehicle-1 & Degrees \\
\hline$\Psi$ & Approach Angle Vehicle-2 & Degrees \\
\hline$\theta$ & Departure Angle Vehicle-1 & Degrees \\
\hline$\phi$ & Departure Angle Vehicle-2 & Degrees \\
\hline $\mathrm{S}_{1}$ & Pre-Collision Speed Vehicle-1 & Miles-per-hour (mph) \\
\hline $\mathrm{S}_{2}$ & Pre-Collision Speed Vehicle-2 & Miles-per-hour (mph) \\
\hline $\mathrm{S}_{3}$ & Post Collision Speed Vehicle-1 & Miles-per-hour (mph) \\
\hline $\mathrm{S}_{4}$ & Post Collision Speed Vehicle-2 & Miles-per-hour (mph) \\
\hline $\mathrm{e}$ & Coefficient of Restitution & N/A \\
\hline
\end{tabular}

\section{REFERENCES}

- Bosch. "PDF." 6 Sept. 2018.

- Bosch. "PDF." 7 Sept. 2018.

- Daily, John, et al. Fundamentals of Traffic Crash Reconstruction. Vol. 2, Institute of Police Technology and Management, 2014.

- Florida Highway Patrol. Equation Handbook for Traffic Homicide Investigators. Equation Handbook for Traffic Homicide Investigators, Florida Highway Patrol, 2004.

- Rivers, R W. Traffic Accident Investigation. 2nd ed., Institute of Police Technology and Management, 1995.

- REC-TEC Professional Accident Reconstruction Software 


\section{APPENDICES}

\section{Momentum Worksheet}

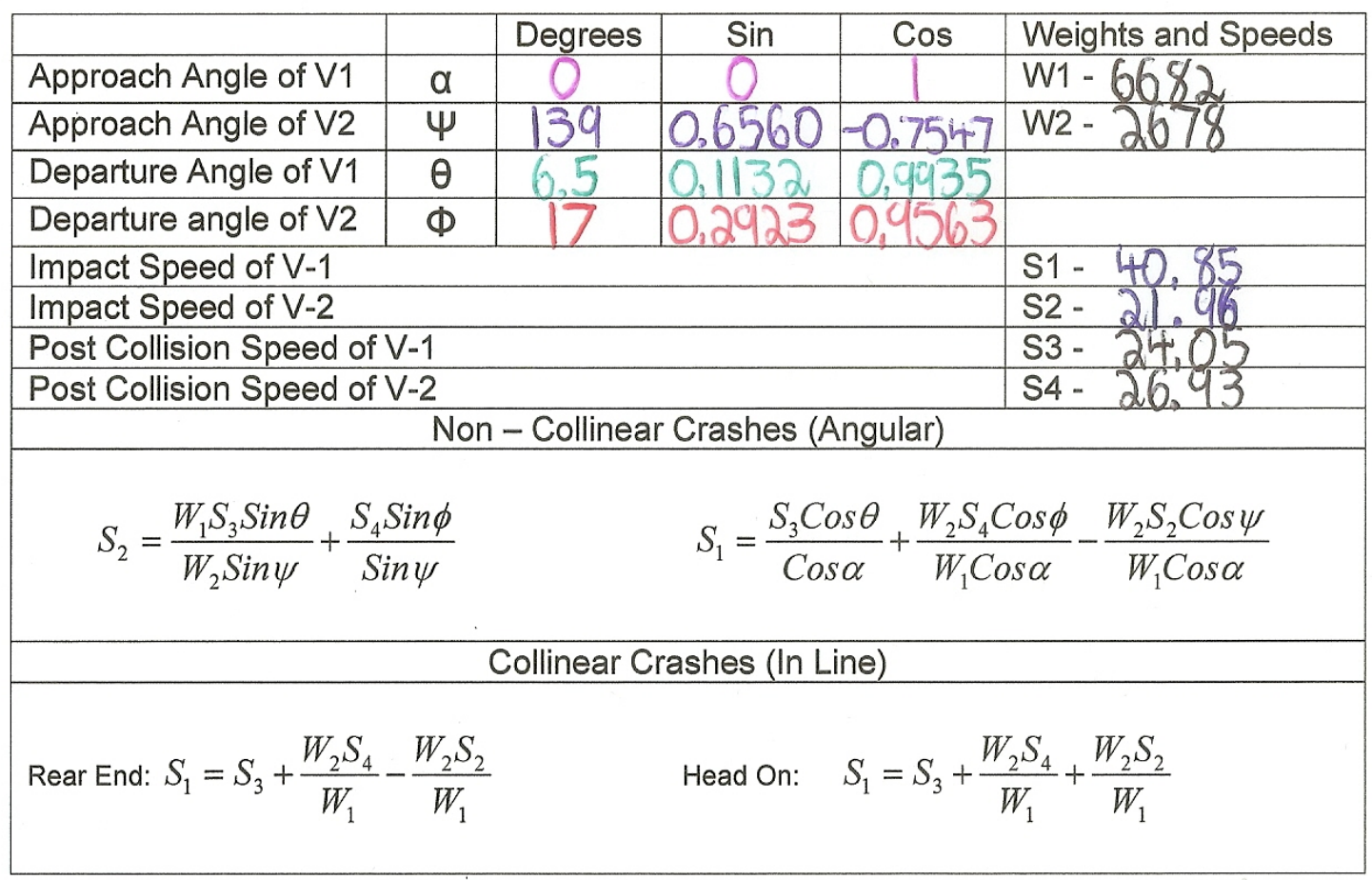


Undergraduate Journal of M athematical M odeling: One + Two, Vol. 11, Iss. 2 [2021], Art. 2

\section{Crash Diagram}

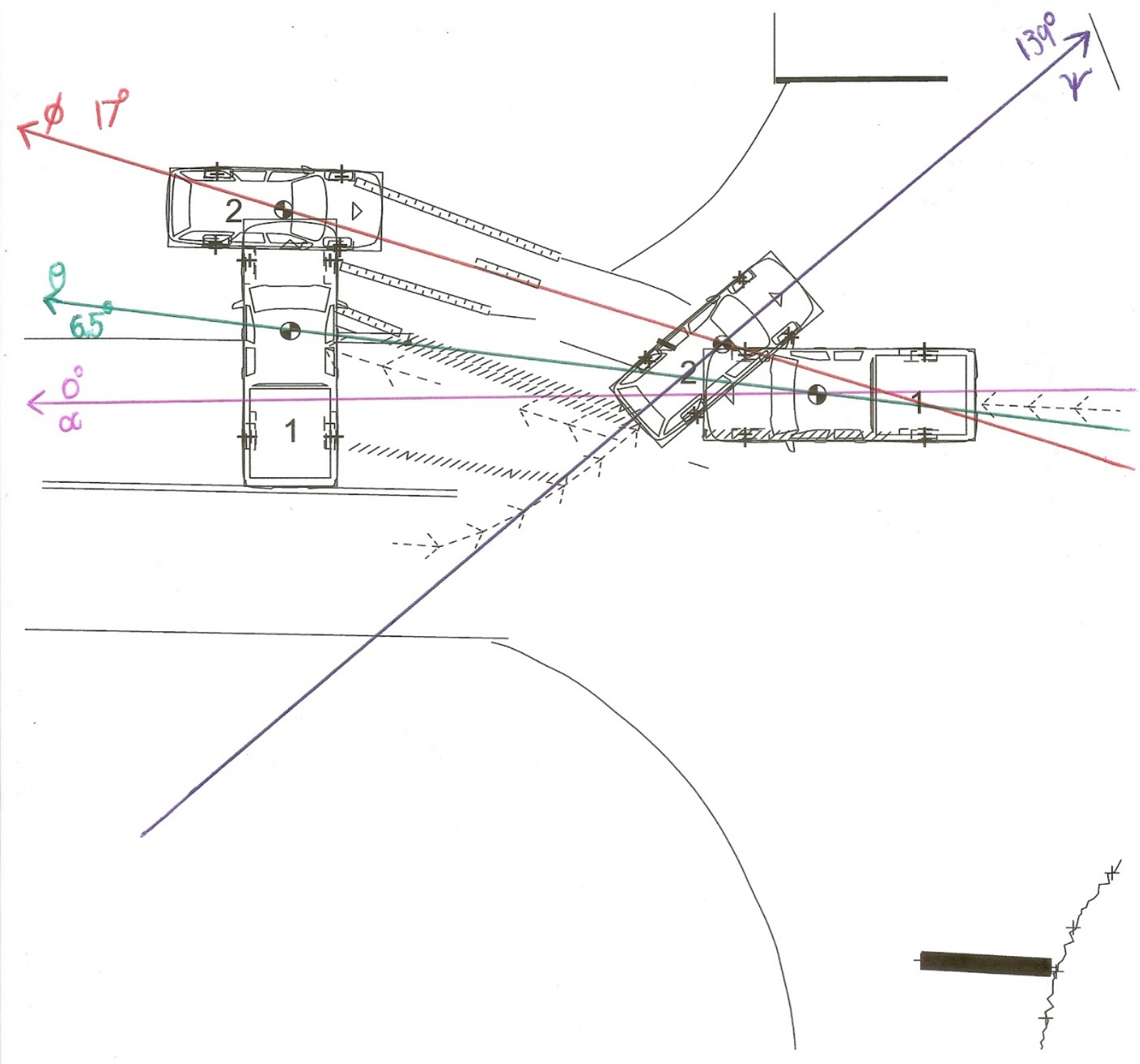


Covert: Mathematical Reconstruction of a Traffic Crash

7

1. Pre-collision speed vehide-2

$$
\begin{aligned}
& S_{2}=\frac{\left(W_{1}\right)\left(S_{3}\right)(\sin \theta)}{\left(W_{2}\right)(\operatorname{Sin} \psi)}+\frac{\left(S_{1}\right)(\sin \phi)}{\operatorname{Sin} \psi} \\
& S_{2}=\frac{(6682)(24.05)(0,1132)}{(2678)(0,6560)}+\frac{(26.05)(0,2923)}{0,6560} \\
& S_{2}=\frac{18191.4777}{1756,7860}+\frac{7.61144}{0,6560} \\
& S_{2}=10,3549+11,6073=21.96 \mathrm{mph}
\end{aligned}
$$

2. Pre-colision speed venice - 1

$$
\begin{aligned}
& S_{1}=\frac{\left(S_{2}\right)(\operatorname{Cos} \theta)}{\operatorname{Cos} \alpha}+\frac{\left(W_{2}\right)\left(S_{1}\right)(\operatorname{Cos} \phi)}{\left(W_{1}\right)(\operatorname{Cos} \alpha)}-\frac{\left(W_{)}\right)\left(S_{2}\right)(\operatorname{Cos} \psi)}{\left(W_{1}\right)(\cos \alpha)} \\
& S_{1}=\frac{(24.05)(0.9935)}{1}+\frac{(2678)(26.93)(0.9563)}{(6682)(1)}-\frac{(266)(28,166)(-0.7547)}{(6682)(1)} \\
& S_{1}=\frac{23.8936}{1}+\frac{68966.9598}{6682}+\frac{44383.0617}{6682} \\
& S_{1}=23,8936+10,3213+6,6421=40,85 \mathrm{mph}
\end{aligned}
$$

Produced by The Berkeley Electronic Press, 2021 
Undergraduate Journal of M athematical M odeling: One + Two, Vol. 11, Iss. 2 [2021], Art. 2

3. Coefficient of Restitution
$e=\frac{\left|S_{3}-S_{4}\right|}{\left|S_{1}-S_{2}\right|}$
$e=\frac{24,05-26,93 \mid}{40,85-21,96 \mid}$
$e=\frac{-2,88 \mid}{|18,80|}=\frac{2.88}{18,89}=0,15$

\section{Vector Sum Analysis My Calculations}

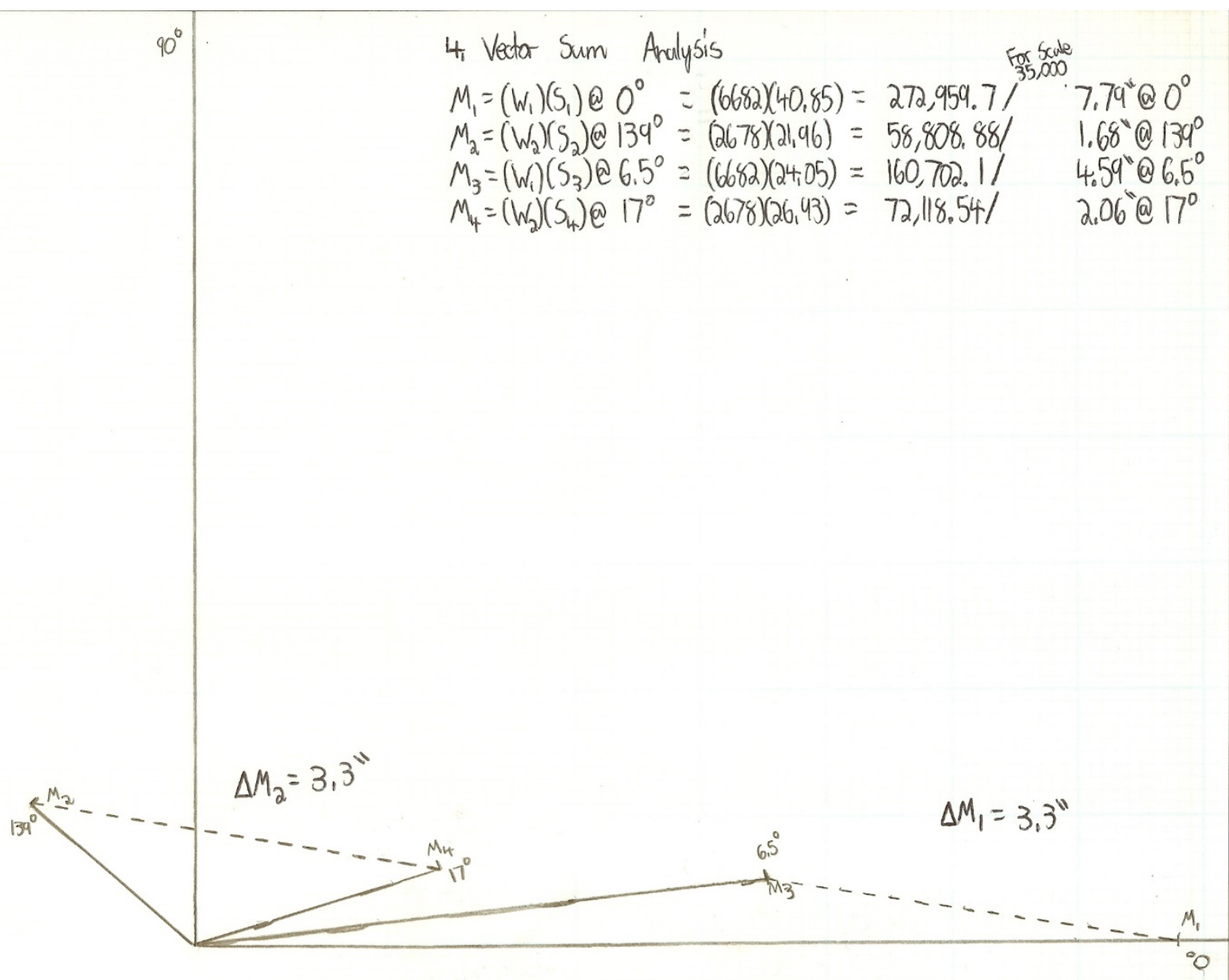




\section{Vector Sum Analysis Computer Analysis}

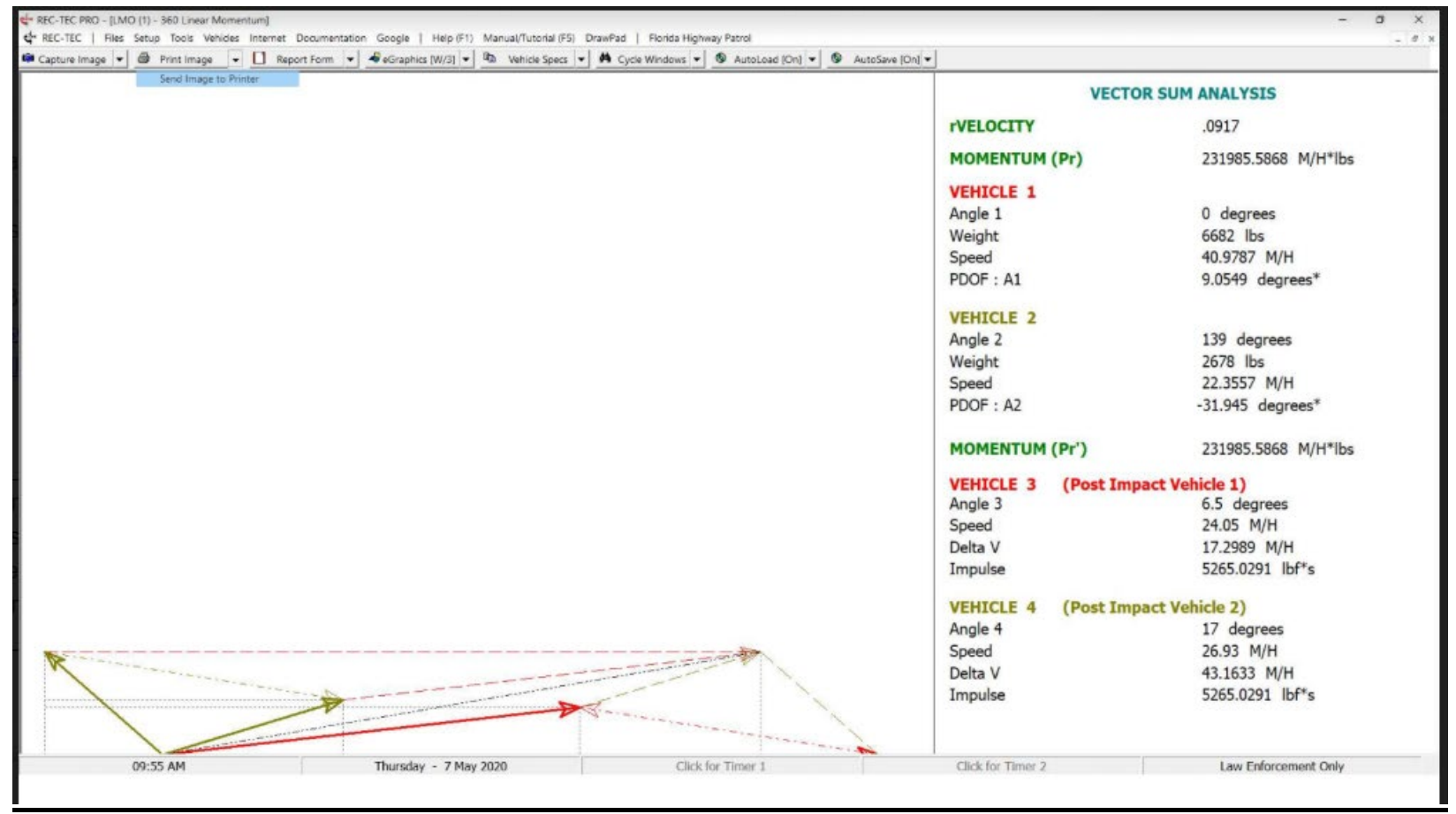

\section{Rec-Tec Data}

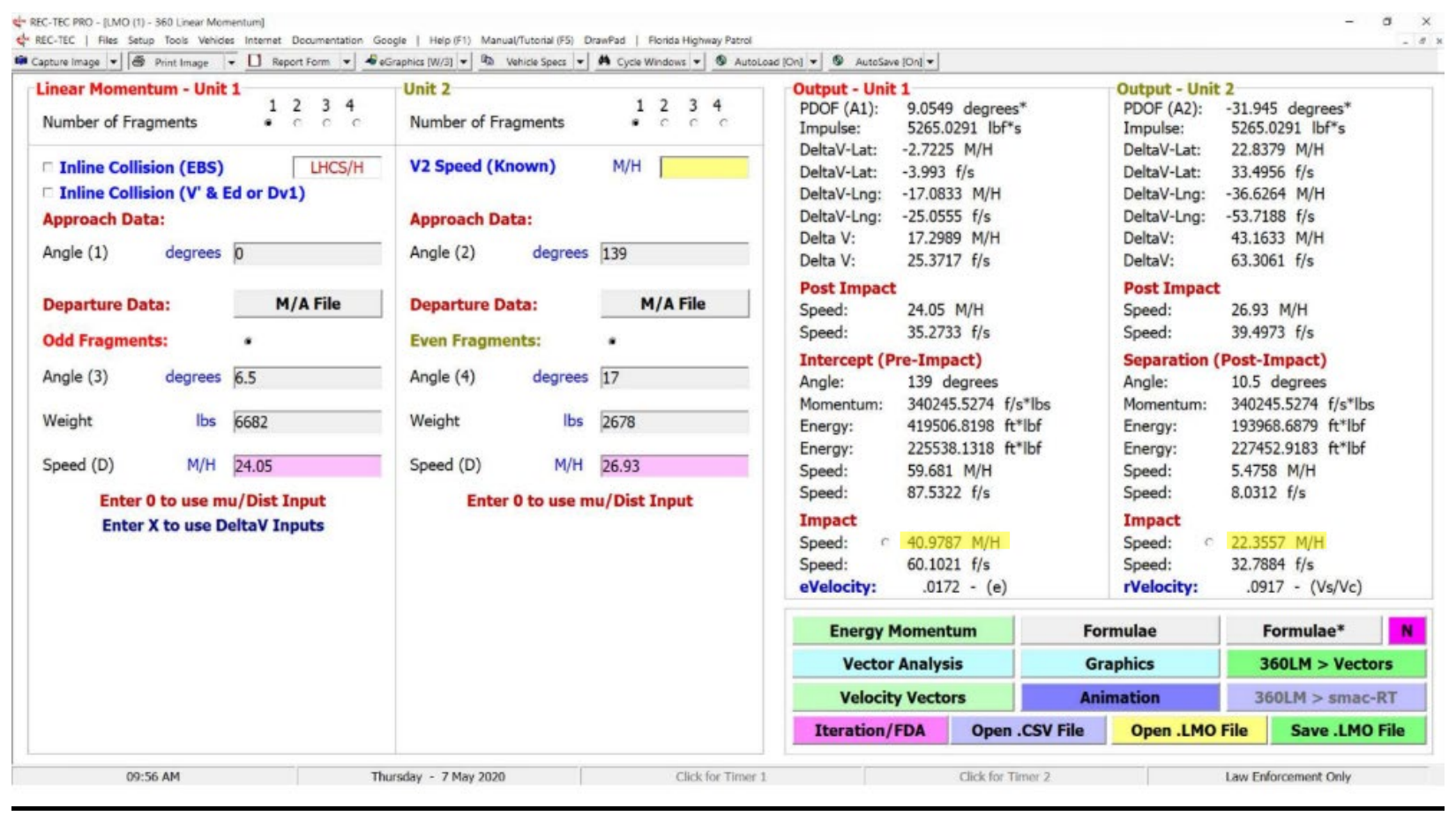




\section{Vehicle-1 Crash Data Retrieval}

Pre-Crash Data (Most Recent Event - table 1 of 3)

(the most recent sampled values are recorded prior to the event)

\begin{tabular}{|c|c|c|c|c|c|c|c|c|c|}
\hline $\begin{array}{l}\text { Time } \\
\text { Stamp } \\
\text { (sec) }\end{array}$ & $\begin{array}{l}\text { Pre-Crash } \\
\text { Recorder } \\
\text { Status }\end{array}$ & $\begin{array}{c}\text { Speed, } \\
\text { Vehicle } \\
\text { Indicated } \\
\text { (MPH [km/h]) }\end{array}$ & $\begin{array}{c}\text { Accelerator } \\
\text { Pedal, } \\
\% \text { Full }\end{array}$ & $\begin{array}{l}\text { Engine } \\
\text { Throttle, } \\
\% \text { Full }\end{array}$ & $\begin{array}{c}\text { Service } \\
\text { Brake }\end{array}$ & $\begin{array}{c}\text { Engine } \\
\text { RPM }\end{array}$ & $\begin{array}{c}\text { ABS } \\
\text { Activity }\end{array}$ & $\begin{array}{l}\text { Stability } \\
\text { Control }\end{array}$ & $\begin{array}{l}\text { Steering } \\
\text { Input (deg) }\end{array}$ \\
\hline-5.0 & Complete & $66[106]$ & 63 & SNA & Off & 1,460 & No & On & 8 \\
\hline-4.9 & Complete & $66[106]$ & 63 & SNA & Off & 1,458 & No & On & 9 \\
\hline-4.8 & Complete & $66[106]$ & 63 & SNA & Off & 1,455 & No & On & 10 \\
\hline-4.7 & Complete & $66[106]$ & 63 & SNA & Off & 1,452 & No & On & 10 \\
\hline-4.6 & Complete & $66[106]$ & 63 & SNA & Off & 1,454 & No & On & 10 \\
\hline-4.5 & Complete & $66[106]$ & 63 & SNA & Off & 1,452 & No & On & 11 \\
\hline-4.4 & Complete & $66[106]$ & 63 & SNA & Off & 1,457 & No & On & 11 \\
\hline-4.3 & Complete & $66[106]$ & 63 & SNA & Off & 1,458 & No & On & 11 \\
\hline-4.2 & Complete & $66[106]$ & 63 & SNA & Off & 1,445 & No & On & 11 \\
\hline-4.1 & Complete & $66[106]$ & 63 & SNA & Off & 1,450 & No & On & 11 \\
\hline-4.0 & Complete & $66[106]$ & 63 & SNA & Off & 1,447 & No & On & 11 \\
\hline-3.9 & Complete & $66[106]$ & 63 & SNA & Off & 1,449 & No & On & 11 \\
\hline-3.8 & Complete & $66[106]$ & 63 & SNA & Off & 1,451 & No & On & 11 \\
\hline-3.7 & Complete & $66[106]$ & 63 & SNA & Off & 1,444 & No & On & 11 \\
\hline-3.6 & Complete & $66[106]$ & 63 & SNA & Off & 1,453 & No & On & 10 \\
\hline-3.5 & Complete & $65[105]$ & 63 & SNA & Off & 1,447 & No & On & 10 \\
\hline-3.4 & Complete & $65[105]$ & 63 & SNA & Off & 1,443 & No & On & 10 \\
\hline-3.3 & Complete & $66[105]$ & 63 & SNA & Off & 1,448 & No & On & 10 \\
\hline-3.2 & Complete & $66[105]$ & 63 & SNA & Off & 1,441 & No & On & 11 \\
\hline-3.1 & Complete & $65[105]$ & 63 & SNA & Off & 1,450 & No & On & 11 \\
\hline-3.0 & Complete & $66[106]$ & 63 & SNA & Off & 1,454 & No & On & 11 \\
\hline-2.9 & Complete & $66[106]$ & 63 & SNA & Off & 1,452 & No & On & 11 \\
\hline-2.8 & Complete & $66[106]$ & 63 & SNA & Off & 1,447 & No & On & 15 \\
\hline-2.7 & Complete & $65[105]$ & 63 & SNA & Off & 1,441 & No & On & 16 \\
\hline-2.6 & Complete & $65[105]$ & 63 & SNA & Off & 1,451 & No & On & 15 \\
\hline-2.5 & Complete & $66[105]$ & 63 & SNA & Off & 1,456 & No & On & 15 \\
\hline-2.4 & Complete & $66[106]$ & 63 & SNA & Off & 1,455 & No & On & 15 \\
\hline-2.3 & Complete & $66[106]$ & 63 & SNA & Off & 1,449 & No & On & 18 \\
\hline-2.2 & Complete & $66[106]$ & 63 & SNA & Off & 1,444 & No & On & 20 \\
\hline-2.1 & Complete & $66[106]$ & 62 & SNA & Off & 1,448 & No & On & 20 \\
\hline-2.0 & Complete & $66[106]$ & 61 & SNA & Off & 1,454 & No & On & 18 \\
\hline-1.9 & Complete & $66[106]$ & 61 & SNA & Off & 1,456 & No & On & 16 \\
\hline-1.8 & Complete & $66[106]$ & 61 & SNA & Off & 1,455 & No & On & 15 \\
\hline-1.7 & Complete & $66[106]$ & 61 & SNA & Off & 1,459 & No & On & 13 \\
\hline-1.6 & Complete & $66[106]$ & 61 & SNA & Off & 1,449 & No & On & 11 \\
\hline-1.5 & Complete & $66[106]$ & 61 & SNA & Off & 1,451 & No & On & 9 \\
\hline-1.4 & Complete & $66[106]$ & 8 & SNA & Off & 1,441 & No & On & 3 \\
\hline-1.3 & Complete & $65[105]$ & 0 & SNA & Off & 1,434 & No & On & -8 \\
\hline-1.2 & Complete & $63[102]$ & 0 & SNA & On & 1,382 & No & Engaged & -25 \\
\hline-1.1 & Complete & $60[97]$ & 0 & SNA & On & 1,319 & Yes & On & -19 \\
\hline-1.0 & Complete & 57 [91] & 0 & SNA & On & 1,232 & Yes & On & -9 \\
\hline-0.9 & Complete & 56 [89] & 0 & SNA & On & 1,195 & Yes & On & -12 \\
\hline-0.8 & Complete & $54[87]$ & 0 & SNA & On & 1,227 & Yes & On & -35 \\
\hline-0.7 & Complete & $51[83]$ & 0 & SNA & On & 1,118 & Yes & On & -57 \\
\hline-0.6 & Complete & $49[79]$ & 0 & SNA & On & 1,031 & Yes & On & -51 \\
\hline-0.5 & Complete & $45[73]$ & 0 & SNA & On & 1,025 & Yes & On & -28 \\
\hline-0.4 & Complete & $43[69]$ & 0 & SNA & On & 1,035 & Yes & On & 4 \\
\hline-0.3 & Complete & $44[71]$ & 0 & SNA & On & 1,097 & Yes & On & 32 \\
\hline-0.2 & Complete & $42[67]$ & 0 & SNA & On & 949 & Yes & On & 46 \\
\hline-0.1 & Complete & $37[60]$ & 0 & SNA & On & 789 & Yes & On & 39 \\
\hline
\end{tabular}

Skid mark on scene supports drive tire may be traveling slower than vehicle actually is. 


\section{Vehicle-2 Crash Data Retrieval}

\section{(A) BOSCH}

C D CRASH DATA

\begin{tabular}{|c|c|c|c|c|c|c|c|c|c|}
\hline $\begin{array}{c}\text { Times } \\
\text { (sec) }\end{array}$ & $\begin{array}{l}\text { Speed } \\
\text { vehicle } \\
\text { indicated } \\
\text { MPH [km/h] }\end{array}$ & $\begin{array}{c}\text { Accelerator } \\
\text { pedal, } \\
\% \text { full }\end{array}$ & $\begin{array}{c}\text { Service } \\
\text { brake, } \\
\text { on/off }\end{array}$ & $\begin{array}{c}\text { Engine } \\
\text { RPM }\end{array}$ & $\begin{array}{c}\text { ABS activity } \\
\text { (engaged, } \\
\text { non-engaged) }\end{array}$ & $\begin{array}{c}\text { Brake } \\
\text { Powertrain } \\
\text { Torque } \\
\text { Request }\end{array}$ & $\begin{array}{l}\text { Driver } \\
\text { Gear } \\
\text { Selection }\end{array}$ & $\begin{array}{c}\text { Traction } \\
\text { Control via } \\
\text { Brakes }\end{array}$ & $\begin{array}{l}\text { Wheel } \\
\text { Torque }\end{array}$ \\
\hline-5.0 & $29[46]$ & 0.0 & On & 1,228 & non-engaged & No & Drive & non-engaged & -252 \\
\hline-4.5 & $27[44]$ & 0.0 & On & 1.178 & non-engaged & No & Drive & non-engaged & -252 \\
\hline-4.0 & $26[42]$ & 0.0 & On & 1,120 & non-engaged & No & Drive & non-engaged & -256 \\
\hline-3.5 & $24[39]$ & 0.0 & On & 1,026 & non-engaged & No & Drive & non-engaged & -264 \\
\hline-3.0 & $23[37]$ & 0.0 & On & 956 & non-engaged & No & Drive & non-engaged & -260 \\
\hline-2.5 & $21[34]$ & 0.0 & On & 934 & non-engaged & No & Drive & non-engaged & -164 \\
\hline-2.0 & $19[31]$ & 0.0 & On & 854 & non-engaged & No & Drive & non-engaged & -68 \\
\hline-1.5 & $17[28]$ & 0.0 & On & 828 & non-engaged & No & Drive & non-engaged & -44 \\
\hline-1.0 & $16[25]$ & 0.0 & On & 806 & non-engaged & No & Drive & non-engaged & -56 \\
\hline-0.5 & $14[23]$ & 0.0 & On & 788 & non-engaged & No. & Drive & non-engager & -84 \\
\hline 0.0 & $14[22]$ & 0.0 & Off & 742 & non-engaged & No & Drive & non-engaged & -80 \\
\hline
\end{tabular}

There is a (.5) second delay from last data point and impact, therefore Vehicle could have accelerated to a higher speed. 